\title{
Recent advances in laser surface treatment of titanium alloys
}

\author{
J. J. Candel ${ }^{\mathrm{a})}$ and V. Amigó \\ ITM Instituto de Tecnologia de Materiales, UPV, Valencia, Spain
}

(Received 15 November 2010; accepted for publication 14 March 2011; published 31 March 2011)

This paper reviews progress over the last five years in the field of laser surface modification of titanium alloys. The authors analyze the effect of new laser technologies and new materials as tools for improving surface properties-specifically, biocompatibility and resistance to wear, corrosion, and high temperatures. The authors discuss the effect of laser processing parameters on the microstructure and compare the results obtained by various researchers. Therefore, an overview of the difficulties involved in the laser processing of titanium is provided with a discussion of future prospects. (C) 2011 Laser Institute of America.

Key words: Laser surface modification, titanium alloys, functional gradient material

\section{INTRODUCTION}

Titanium alloys possess excellent properties such as low density and high levels of heat and mechanical resistance, as well as excellent biocompatibility. Moreover, surface treatments can further enhance the performance and increase the applications for these alloys. There is growing interest in developing new coatings for titanium alloys and the laser is one of the most promising tools in this field.

Tian et al. published an excellent review paper in 2005 that detailed progress in the field of laser surface treatment for titanium alloys. The paper also discussed the problems associated with laser processing and set out the challenges for the coming years. ${ }^{1}$

The incorporation of new laser systems for industry and research such as high-power diode lasers (HPDLs) and fiber lasers has been an important breakthrough. Both systems offer improved energy efficiency, better wavelengths for metal processing, and excellent beam quality. These new developments may herald further breakthroughs in the laser surface treatment of titanium and its alloys. ${ }^{2,3}$

There have also been many advances in the field of materials. New laser coatings based on intermetallic compounds, ceramics, metal matrix composites (MMCs), and functional gradient materials (FGMs) have been developed.

New laser technologies and new materials for the surface treatment of titanium alloys have been vigorously researched over the past five years. This paper summarizes the results published for titanium substrates and offers an overview of the state of art. In addition, we examine to what extent the issues raised by Tian et al. ${ }^{1}$ in 2005 have been resolved.

\section{IMPROVEMENTS IN BIOMATERIALS}

Titanium alloys offer excellent properties as implant materials and are widely used. However, various types of laser treatment can be used to enhance the biological activity of titanium or improve its poor resistance to wear.

${ }^{a)}$ Electronic mail: juacanbo@doctor.upv.es

\section{A. Bioactive coatings}

Hydroxyapatite (HA) improves the biocompatibility of titanium and Atmospheric Plasma Spraying (APS) and is widely used due to its high productivity. However, other coating techniques offer promising results-such as pulsed laser deposition ${ }^{4}$ - which takes advantage of the compressive impact of the beam to achieve a higher density. Both techniques can be combined by using APS to project the surface coating and laser surface remelting (LSR) to consolidate and improve adherence. ${ }^{5}$ However, major difficulties have been encountered in these processes, and these include changes in the components, cracking, and poor adhesion between the coating and substrate. ${ }^{6,7}$

A possible solution to these problems is the development of laser cladding with FGMs. The objective is to obtain a calcium phosphate gradient bioceramic (HA) on a Ti6Al4V substrate. To achieve higher density and lower thermal stresses during cooling, successive layers of elemental mixture of titanium and calcium phosphate powder are applied, thereby increasing the weighed ceramic content by between $20 \%$ and $100 \%$. In addition, changes are being studied in the composition of the powder that compensate for the loss of phosphorus during processing and prompt the formation of bioactive phases. ${ }^{8-10}$ The result is an improved metallurgical bond with the substrate (Fig. 1) and a gradual increase in hardness that facilitates relaxation of tensions and osseointegration. ${ }^{9}$ In addition, process control can further prompt the formation of HA and tricalcium $\beta$-phosphate, which are responsible for cell proliferation (Fig. 2). Reducing the formation of undesirable phases such as $\mathrm{CaO}$ and $\mathrm{CaTiO}_{3}$ is one of the objectives for future work. ${ }^{10}$

Bioactive glass is an interesting material for coatings. The material is notable for its bioactivity in aqueous mediums; however, its fragility limits its application, especially in those techniques that induce thermal stresses during processing. Comesaña et al. studied the production of this type of coatings using $\mathrm{Nd}$ :yttrium aluminum garnet (Nd:YAG) laser cladding. ${ }^{11}$ To achieve a uniform coating it 


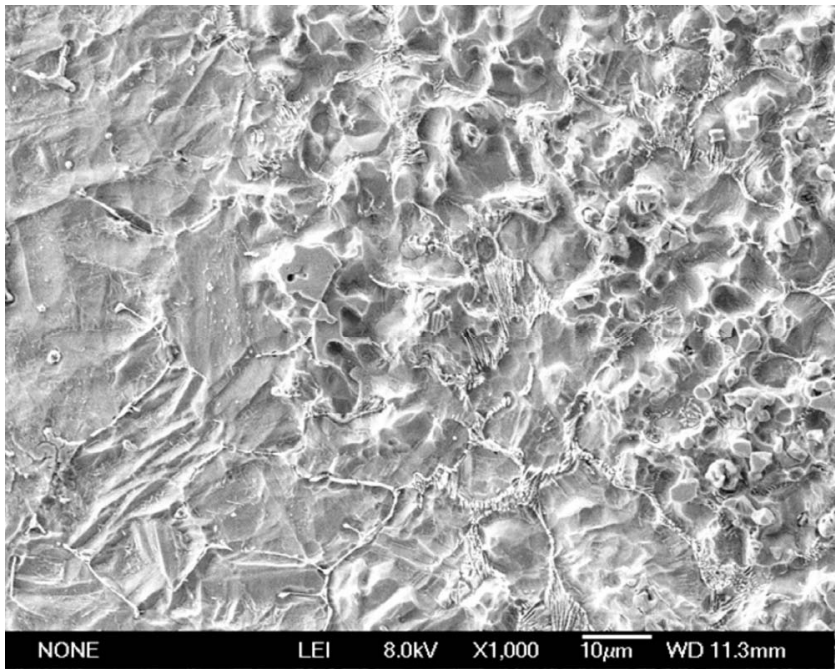

FIG. 1. Micrograph of the interface between the substrate of Ti6Al4V and the graded bioceramic coating. The image shows an excellent metallurgical bonding and absence of pores or cracks [courtesy of Zheng et al. (Refs. 8 and 10)].

is important to use a bioglass with a gradual wetting angletemperature evolution. Thermal stresses should also be minimized, and this requires adjusting the thermal expansion coefficient of the material. Both aspects can only be achieved by changing the glass composition. Some commercial glasses (such as 45S5) offer excellent bioactivity properties but also have other properties that are inferior to other glasses (such as S520) when processed by laser (Table I). For these reasons, the parameter window is very small, with power ratings between 50 and $150 \mathrm{~W}$, and low processing speeds $(V=1-4 \mathrm{~mm} / \mathrm{s})$ are used.

Finally, a simple technique that produces an alloy using a gas-activated laser can improve the osseointegration of metallic implants anchored directly to the bone. The objective is to increase the roughness and generate a tenacious bioactive surface that improves anchorage, facilitates wettability by biological fluids, and accelerates cellular response. The higher absorption coefficients offered by HPDLs suggest interesting possibilities for this type of surface heat treatment. The results indicate that a correct control of the energy applied and the pressure of the oxygen supplied as active process gas can enable the production of rough surfaces. These surfaces are formed by $\mathrm{Ti}+\mathrm{TiO}_{2}$, and this facilitates greater osseointegration than untreated surfaces-better even than implants whose roughness has been enhanced by mechanical roughing. ${ }^{12}$

TABLE I. Composition in mol \% of the glasses studied by Comesaña $e t$ al. (Ref. 11).

\begin{tabular}{lccccc}
\hline \hline & $\mathrm{SiO}_{2}$ & $\mathrm{CaO}$ & $\mathrm{Na}_{2} \mathrm{O}$ & $\mathrm{P}_{2} \mathrm{O}_{5}$ & $\mathrm{~K}_{2} \mathrm{O}$ \\
\hline $45 \mathrm{~S} 5$ & 46.1 & 26.9 & 24.4 & 2.6 & \\
$\mathrm{~S} 520$ & 52.0 & 18.0 & 20.9 & 2.0 & 7.1 \\
\hline \hline
\end{tabular}

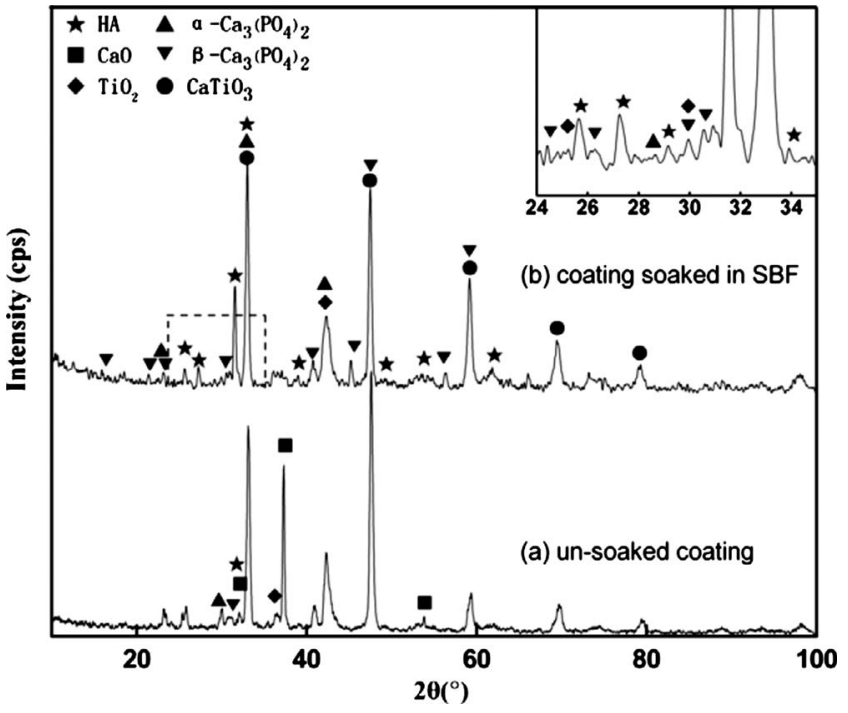

FIG. 2. X-ray diffraction patterns of HA laser-cladded coating (a) unsoaked and (b) soaked in simulated body fluid for 14 days [courtesy of Zheng et al. (Refs. 8 and 10)].

\section{B. Bioinert hard coatings}

Improving the wear resistance of load-bearing implants such as total hip replacement is one of the areas where laser processing has been applied, because surface faults are one of the major causes of failure in these joints. There are currently two lines of research: the production of hard ceramic layers and the "in situ" formation of very strong intermetallic compounds.

Ceramics based on $\mathrm{Al}_{2} \mathrm{O}_{3}, \mathrm{TiO}_{2}$, and $\mathrm{ZrO}_{2}$ satisfy all the requirements for this type of implant. Their great strength, as well as their ability to absorb water, gives them excellent tribological properties. Two techniques are used for their application such as coatings on titanium alloys: plasma spraying (APS) followed by LSR and application with a gradual function by laser cladding.

Progress has been made in the APS+LSR technique with the use of nanostructured ceramics. Specifically, Wang et al. studied $\mathrm{Al}_{2} \mathrm{O}_{3}+13 \% \mathrm{TiO}_{2}$. A relatively sparse coating has been obtained with a lamellar-type structure and adhesion problems after processing by APS. However, optimized laser processing favors recrystallization and the formation of equiaxed grains. This is because the nanoparticles act as stabilizing elements in the partially melted zones and the rapid cooling rate imposed by the laser prevents grain growth. ${ }^{13}$

Laser cladding processing, although less productive than APS, enables the application of thicker coatings with a gradual function. Balla et al. investigated coatings based on $\mathrm{Ti} / \mathrm{TiO}_{2}$ and $\mathrm{Zr} / \mathrm{ZrO}_{2}$ with promising results. ${ }^{14,15}$ In an initial study, several layers of different powder mixtures of $\mathrm{Ti}$ and $\mathrm{TiO}_{2}$ were laid using a dual powder feed hopper. The $\mathrm{TiO}_{2}$ content varied between $50 \%$ and $90 \%$ by weight. It was found that tensions in the coating could be reduced, and a gradual increase in hardness was achieved. In a second paper, $\mathrm{Zr}$ powder was used with a mixture of argon and oxygen as the process gases. In this way, in situ generation 


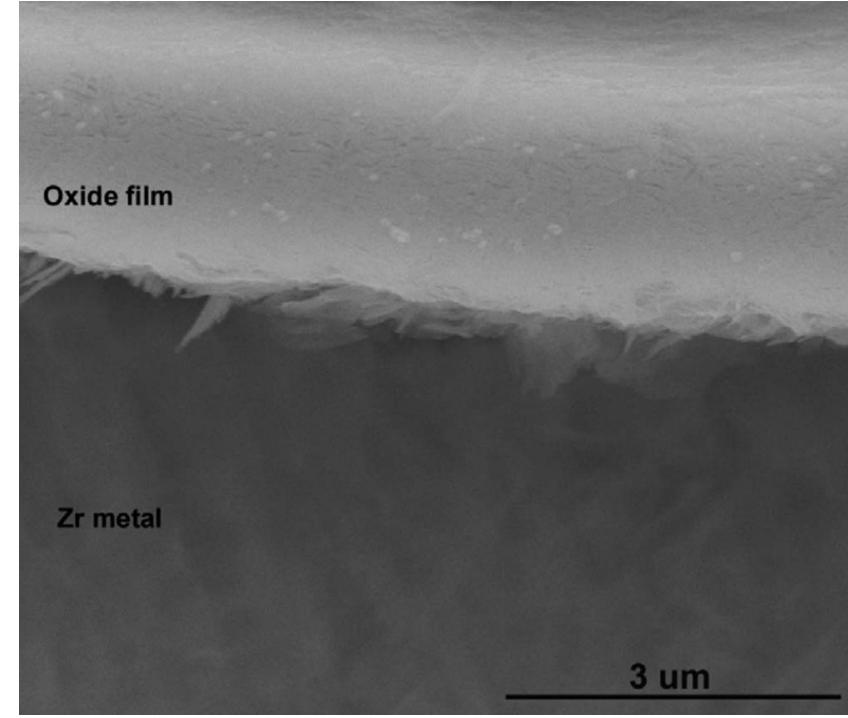

FIG. 3. High magnification image showing a strong interface between the $\mathrm{Zr}$ coating and $\mathrm{ZrO}_{2}$ film processed at $200 \mathrm{~W}, 4 \% \mathrm{O}_{2}$ [courtesy of Balla et al. (Refs. 14 and 15)].

was used for hard ceramic compounds $\left(\mathrm{ZrO}_{2}\right)$ by reaction with oxygen as an active gas. Cracks were reduced, and the roughness and hardness of the coating were controlled through strict control of the power applied and the pressure of the oxygen for each layer (Fig. 3). The result in both cases was a significant reduction in the friction coefficient and wear.

The formation of intermetallic compounds in situ is another approach for improving the surface properties of titanium. Three alloying elements are especially important: cobalt, ${ }^{16,17}$ nickel, $^{18}$ and niobium. ${ }^{19}$

Cobalt reacts during laser processing to form $\mathrm{TiCo} / \mathrm{Ti}_{2} \mathrm{Co}$, and this substance hardens the matrix by precipitation. TiCo has a high resistance and high elastic modulus, while $\mathrm{Ti}_{2} \mathrm{Co}$ is harder than $800 \mathrm{HV}$. Xue and Wang developed coatings based on a mixture of elemental powders $(\mathrm{Ti}+40 \% \mathrm{Co})$ that offer a significant improvement in wear resistance by reducing adhesive behavior. ${ }^{16}$ The increase in cobalt through gradual application in successive layers can further improve the tribological properties and reduce the generation of stresses and defects. However, corrosion tests show that cobalt may worsen the behavior when faced with holes, and the results are inconclusive. ${ }^{17}$

Nickel alloy can form compounds of $\mathrm{TiNi} / \mathrm{Ti}_{2} \mathrm{Ni}$ with exceptional properties. TiNi is one of these compounds and is known for its toughness, elasticity, and a shape memory that can accommodate deformations in joints due to impact loads. $\mathrm{Ti}_{2} \mathrm{Ni}$ is harder and can act as a reinforcement particle to improve the wear resistance of a tenacious matrix formed with TiNi. Gao and Wang found that laser cladding processing an elemental powder mixture (52Ti48Ni) produces a matrix of martensite TiNi needles with fine precipitates of $\mathrm{Ti}_{2} \mathrm{Ni}$. This composite material has excellent wear resistance, although controlling the microstructure is a challenge for future work. ${ }^{18}$

More recently, in 2010, work began with Ti45Nb-based alloys. These alloys are notable for their shape memory, high resistance to wear, and improved biocompatibility because of the absence of toxic elements. Moreover, their high cost means that the development of laser coatings using this material would be very useful. A preliminary study employed a $1.1 \mathrm{~kW}$ fiber laser and preplaced powder on steel substrates. Favorable microstructure and a high level of wear resistance mean that this is a promising area for future work. $^{19}$

\section{IMPROVED RESISTANCE TO HIGH TEMPERATURES}

Titanium alloys have a poor resistance to oxidation at temperatures above $600{ }^{\circ} \mathrm{C}$, which prevents their use in some turboprop components. Atmospheric plasma spraying (APS) remains one of the most used techniques for increasing the maximum service temperature, while thermal barrier coating (TBC) is an alternative approach. ${ }^{20}$ Meng et al. worked with laser cladding coatings of NiCoCrAlY on Ti6Al4V and confirmed that it is possible to produce layers with a good metallurgical bond with the substrate and without cracks or pores. Moreover, the substrate becomes twice as hard and more resistant to erosion. ${ }^{21}$ Other alternatives, such as coatings based on Ti-Co-Si intermetallic compounds, can increase resistance to oxidation at temperatures above $800{ }^{\circ} \mathrm{C}$ through the in situ formation of $\mathrm{Ti}_{5} \mathrm{Si}_{3} .{ }^{22}$

In recent years, titanium aluminide ( $\mathrm{TiAl}$ ) has become one of the most promising material for the aviation industry due to excellent mechanical properties at high temperatures. However, resistance to oxidation decreases considerably above $750{ }^{\circ} \mathrm{C}$, and for this reason considerable research effort is being invested in glass ceramic coatings. ${ }^{23}$ In the laser field, efforts are being made to develop techniques of APS combined with laser glazing, as well as laser-assisted chemical deposition.

\section{A. Laser glazing of TBCs}

Laser glazing treatment reduces the roughness, seals the porosity, and creates a controlled segmented crack network. These perpendicular cracks on the surface of a densified coating can increase the thermal shock resistance up to four times due to the accommodation of tensions. ${ }^{24}$ Recent studies by Batista et al. ${ }^{25}$ have shown that the APS laser glazing of $\mathrm{ZrO}_{2}-8$ wt $\% \mathrm{Y}_{2} \mathrm{O}_{3}$ coatings with $\mathrm{CO}_{2}$ systems reduces the defects and inhomogeneity of $\mathrm{Y}_{2} \mathrm{O}_{3}$ caused by thermal spraying. The rapid cooling involved in this process also eliminates the residual monoclinic phase but leaves small traces of phase $t^{\prime}{ }^{26}$ All of the above contribute to a better behavior during oxidation tests in the presence of molten salt at $1000{ }^{\circ} \mathrm{C}$ than that achieved with sprayed condition coatings. $^{27}$

Laser glazing transforms the metastable $\gamma-\mathrm{Al}_{2} \mathrm{O}_{3}$ present in the APS coating to $\alpha-\mathrm{Al}_{2} \mathrm{O}_{3}$. There is also a significant reduction in residual stresses and increased hardness when compared with sprayed coatings (2000 HV). This is achieved by multiple passes with a low power $(500 \mathrm{~W}) \mathrm{CO}_{2}$ laser system at a low forward speed $(3 \mathrm{~mm} / \mathrm{s}){ }^{28}$ 


\section{B. Laser chemical vapor deposition}

Chemical vapor deposition (CVD) coating produces high quality TBCs with a controlled microstructure. However, the process has a low deposition rate that limits its large-scale use. For this reason, an intense effort is being made to increase productivity through a combination of heat treatments during CVD coating.

Laser photolytic CVD has been used for the processing of titanium alloys. During the process the laser beam locally excites the active gases and prompts photochemical reactions. As a result, coating can be achieved three times more quickly and layer thicknesses of $100 \mu \mathrm{m}$ can be produced using Nd:YAG $(P<500 \mathrm{~W})$ lasers. ${ }^{29-32}$

Various oxide-based coatings have been successfully achieved, including $\mathrm{Al}_{2} \mathrm{O}_{3}$ and YSZ. ${ }^{29}$ Thanks to the contribution of laser energy, the process is less dependent on the deposition temperature, and the texture and porosity of the $\alpha-\mathrm{Al}_{2} \mathrm{O}_{3}$ coating can be controlled with promising results. $^{30}$

However, nitride layers may offer better properties for coating $\gamma$-TiAl alloys. ${ }^{31}$ Based on nitrides of transition metals $(\mathrm{CrN}$ and $\mathrm{TiN})$, they reveal excellent resistance to oxidation at temperatures above $900{ }^{\circ} \mathrm{C}$. This is especially true when aluminum is added to form the $\mathrm{Ti}_{1-x} \mathrm{Al}_{x} \mathrm{~N}$ and $\mathrm{Cr}_{1-x} \mathrm{Al}_{x} \mathrm{~N}$ ternary compounds. Nevertheless, the results are not yet conclusive given that various uncontrolled reactions can occur between $\mathrm{N}$ and $\mathrm{Ti}$ during laser processing, and these reactions may deteriorate the properties. ${ }^{32,33}$

\section{IMPROVING RESISTANCE TO WEAR}

The usual mechanism for improving the wear resistance of metals is the addition of hard particles. MMC coatings reinforced with ceramic particles and/or intermetallic compounds $^{34}$ have been developed to achieve this in the field of laser surface treatment.

\section{A. MMCs based on titanium carbide}

$\mathrm{TiC}$ is one of the hardest metal carbides (19.6-31.4 $\mathrm{GPa}$ ) and provides high wear resistance for many alloys. ${ }^{35}$ TiC was widely used with good results during the period of 2000-2005 as reinforcement in the area of laser cladding with a preplaced powder layer for $\mathrm{Ni}-\mathrm{Cr}$ coverings of Ti6Al4V. ${ }^{1}$ These coatings showed good particlereinforcement interaction and excellent resistance to wear and oxidation. However, the problems associated with the adhesion of the powder to the substrate meant that it was necessary to work with high-energy levels $\left(E>4 \mathrm{~kJ} / \mathrm{cm}^{2}\right)$. These high levels caused the dissolution of $\mathrm{TiC}$ and the formation of dendrites. ${ }^{36-38}$ Meng et al. tried to exploit this controlled decomposition using $\mathrm{B}_{4} \mathrm{C}$ powder for in situ composite coatings of $\mathrm{NiCr}$ with a complex-but well scattered-structure that consisted of blocked particles of $\mathrm{TiB}_{2}$, TiC dendrites, and whiskers of $\mathrm{CrB} .^{38}$

More recent studies by Liu et al. indicate that the sliding wear resistance of $\mathrm{TiAl}$ can be improved using $\mathrm{NiCr}$ $+\mathrm{Cr}_{3} \mathrm{C}_{2}$ as a precursor powder. With the addition of $\mathrm{Ti}$ and $\mathrm{Al}$ from the substrate, a matrix of $\operatorname{NiCrAlTi}(\gamma)$ is formed.
This matrix forms a eutectic with $\mathrm{Cr}_{7} \mathrm{C}_{3}$ that reduces the formation of pores and cracks. In addition, a fine dispersion of $\mathrm{TiC}$ is formed because of the combination with $\mathrm{Ti}$ and free $\mathrm{C}$. The wear resistance of the coating at high temperatures $\left(600{ }^{\circ} \mathrm{C}\right)$ is four times greater than that of TiAl. ${ }^{39}$ To achieve this, a covering of $\mathrm{CaF}_{2}$ with Ni-P is made using electroless plating to improve compatibility with $\mathrm{NiCr}$, reduce its buoyancy, and limit decomposition during laser coating. ${ }^{40}$

One option for improving interfacial compatibility between the substrate and coating is the development of titanium matrix MMCs. Cai et al. showed that after the prior adhesion of $\mathrm{Ti}+\mathrm{B}_{4} \mathrm{C}(20 \mathrm{wt} \%)$ powder in a groove and remelting with a $\mathrm{CO}_{2}$ laser in continuous mode, the $\mathrm{B}_{4} \mathrm{C}$ decomposes and forms a finely dispersed mixture of TiB $+\mathrm{TiC}$ in a matrix of titanium martensite. This coating compound forms a strong metallurgical bonds with the substrate and is very hard, although its appearance and consistency are not optimal. ${ }^{41}$ Yang et al. worked with preplaced mixtures of $\mathrm{Ti}+\mathrm{TiCN}(85 \mathrm{wt} \%)$ and $\mathrm{Nd}$ :YAG lasers in impulse mode and were able to improve adhesion and reduce cracks for a high level of reinforcement. However, the results were inconclusive because TiCN decomposes to form $\mathrm{TiC}, \mathrm{TiN}$, and other undesirable compounds such as $\mathrm{TiO}_{2}{ }^{42}$ Moreover, a uniform coating was not obtained during the carburization of Ti6Al4V by bonding with graphite powder and subsequent heat treatment with a Nd:YAG pulsed laser, although a large amount of eutectic TiC was produced. $^{43}$

Coaxial laser cladding is a very powerful technique for producing high quality MMC from hard materials. ${ }^{44}$ However, titanium powder is very reactive with the atmosphere and so is easily oxidized during laser treatment and subsequent cooling. ${ }^{45}$ Overcoming this problem requires a strict control of parameters, especially energy and the amount of powder used, as well as the use of protective gas during the process.

Zhang et al. used a $\mathrm{CO}_{2}$ laser in continuous mode equipped with a coaxial nozzle for powder feeding to generate Ti-based MMC on Ti substrate using laser cladding and the powder blowing technique. The results indicate that it is possible to obtain very dense crack-free coatings using various mixtures of $\mathrm{Ti}+\mathrm{TiC}$ (up to $40 \mathrm{wt} \%$ ). However, the high-energy levels required during the process reduce the final hardness of the coating due to the decomposition of TiC. ${ }^{46}$ In our recently published study we employed a Nd:YAG laser system and used mixtures of Ti6Al4V+TiC $(15,30$, and $60 \mathrm{wt} \%)$ to coat a Ti6Al4V substrate. Thanks to the increased absorption of Nd:YAG and energy control we managed to obtain dense crack-free coatings and reduced heat affects. The dry wear tests indicate that the presence of partially dissolved primary $\mathrm{TiC}$ particles (Fig. 4) provides better wear resistance than coatings requiring greater energy levels. $^{47}$

\section{B. Other MMCs}

$\mathrm{WC}$ is a carbide with excellent properties of toughness and wear resistance. WC also has a thermal expansion 


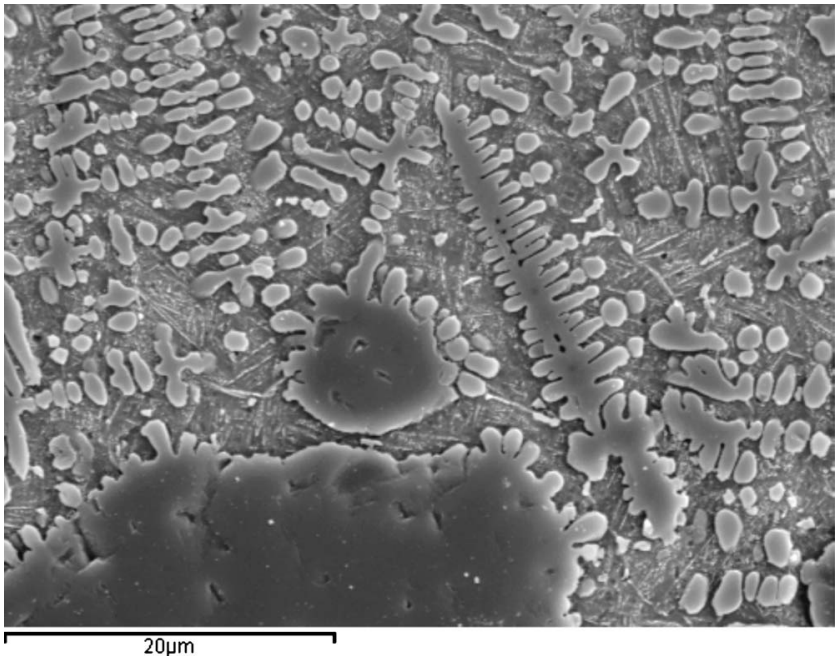

FIG. 4. Scanning electron microscopy micrograph of a Ti6Al4V $+60 \% \mathrm{TiC}$ coating that shows TiC partially diluted in a Ti-matrix.

coefficient much lower than other carbides such as $\mathrm{TiC}$ or SiC. However, WC decomposes easily during laser processing and forms undesirable structures. ${ }^{44}$ In the case of titanium alloys, $\mathrm{W}$ is a $\beta$-stabilizer that improves mechanical properties, and so a small dissolution of WC would not be dramatic. $^{48}$

Various coatings obtained by LC using preplaced MoWC powder with varying WC contents $(0-100$ wt $\%)$ show that virtually all the $\mathrm{WC}$ is dissolved and only the larger $\mathrm{WC}$ particles remain. Moreover, extremely complex dendritic structures are formed, consisting of compounds of Ti-Mo-WC (Fig. 5). ${ }^{49}$

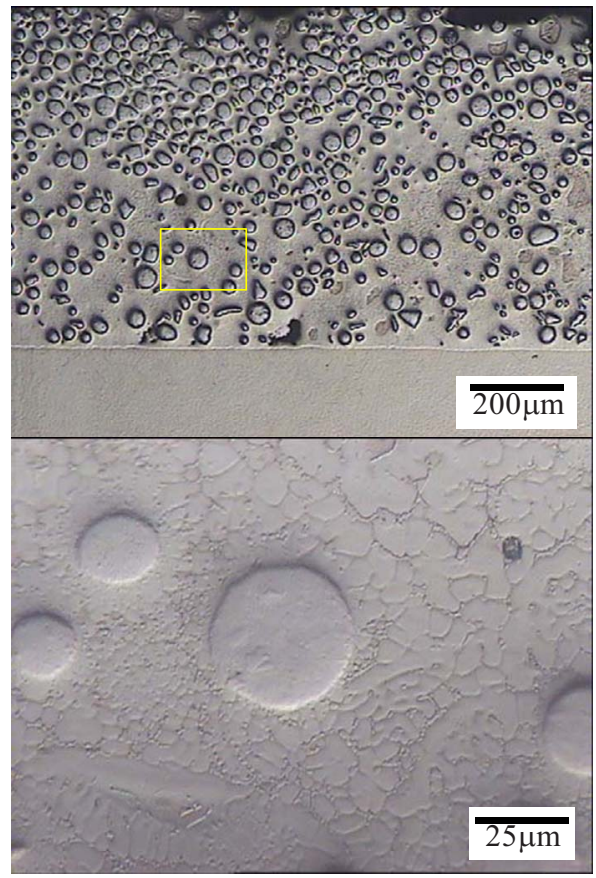

FIG. 5. Cross-section of Ti-25Mo-25WC coating on Ti6Al4V substrate. The partial dissolution of WC can be seen, as well as the complex cellular microstructures formed by the alloy of Ti-Mo-W.

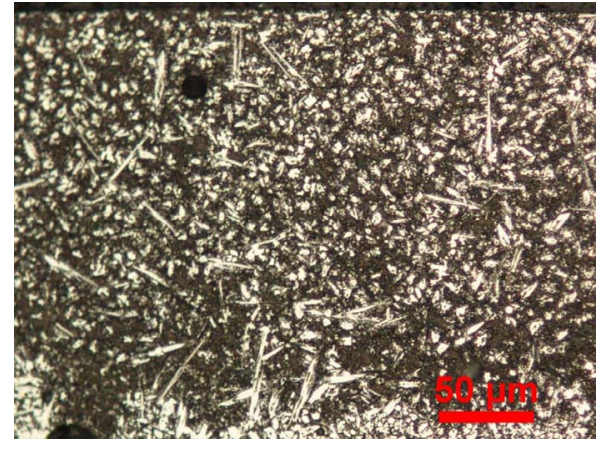

FIG. 6. Cross-section of a coating of $\mathrm{TiAl}+\mathrm{TiB}_{2}$ that reveals the partial decomposition of $\mathrm{TiB}_{2}$ and $\mathrm{TiB}$ holes.

Laser melting injection is one of the most suitable techniques for controlling the dissolution of WC. Thanks to the low thermal conductivity of titanium and the high density of WC, it is possible to place particles in a molten bath generated by the laser while avoiding direct contact with the beam. Various authors have researched the injection of WC in Ti6Al4V and found that the interaction between the molten metal and WCp is the key factor for obtaining a good distribution of particles and a controlled dissolution. ${ }^{50}$ In this way, it is possible to produce a dense and well adhered layer of $\mathrm{TiC}$ around WC particles. ${ }^{51}$

Another alternative is based on $\mathrm{Ti}^{-} \mathrm{TiB}_{2}$ and offers toughness, mechanical strength, and resistance to creep. ${ }^{34}$ The viability of obtaining this type of coating using coaxial laser cladding has been studied. After processing with a $\mathrm{CO}_{2}$ $\mathrm{Ti}+\mathrm{TiB}_{2}\left(5-10\right.$ wt \%) system, it was found that some $\mathrm{TiB}_{2}$ particles decompose to form needle-shaped TiB (Fig. 6). Therefore, the amount of reinforcement and energy provided has a great influence on wear resistance and tenacity. ${ }^{52}$ Small additions of rare earth oxides such as $\mathrm{Ce}_{2} \mathrm{O}_{3}$ and $\mathrm{Y}_{2} \mathrm{O}_{3}$ may play an important role in refining the resulting structure and reducing levels of fragility. ${ }^{53}$

Finally, it is worth noting advances in the development of laser coatings on Ti-TiN. Since the 1990s, it has been known that it is possible to obtain a hard coating of $\mathrm{TiN}$ on titanium by laser alloying with nitrogen gas. ${ }^{54}$ However, this is an unstable process, and it is difficult to obtain thick and dense layers without defects. ${ }^{55}$ Recently, this technique was used with a Nd:YAG pulse laser and various combinations of $\mathrm{Ar} / \mathrm{N}_{2}$ and new Ti-Nb-Zr biomedical alloys. Greater adhesion and hardness were achieved, although a fine network of microscopic cracks also formed due to the formation of $\mathrm{TiN}$ dendrites. ${ }^{56}$ An alternative to this process is $\mathrm{N}_{2}$-assisted laser cladding with titanium powder for in situ formation of TiN in the coating (Fig. 7). Man et al. obtained a dense and crack-free coating on NiTi substrate measuring more than $500 \mu \mathrm{m}$. This reinforcement doubles the wear resistance of the substrate. ${ }^{57}$ The same idea has been used for coatings based on Ti-Al-N that are made from mixtures of $\mathrm{Ti}+\mathrm{Al}+\mathrm{TiN}$ as a powder precursor. The objective is to generate a composite coating of $\mathrm{Ti}_{3} \mathrm{Al} / \mathrm{TiN}$. Results are promising and may be the subject of future work. ${ }^{58}$ 


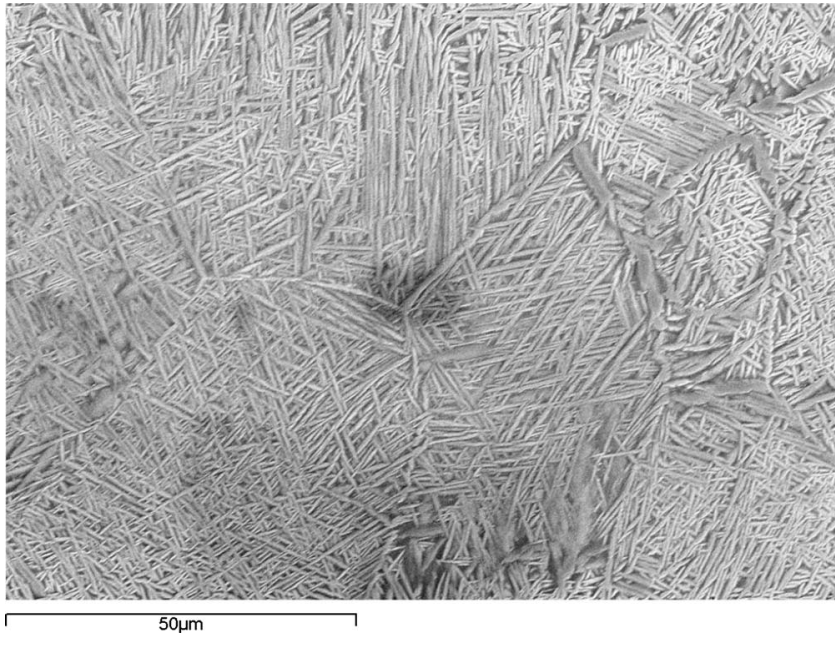

FIG. 7. Detailed image of the microstructure produced on titanium after the nitrogen-assisted laser cladding.

\section{CONCLUDING REMARKS}

New technologies such as diode and fiber lasers offer many advantages; however, these technologies have not been much used in the surface treatment of titanium alloys. The most popular processing techniques continue to be Nd:YAG and $\mathrm{CO}_{2}$ laser processing, and these remain very competitive technologies for the surface remelting of titanium substrates and/or previously deposited coatings.

The use of successive layers of coatings with gradually increasing compositions that are applied in hard and/or fragile phases has been a key strategy for reducing cracks and pores in composite coatings. In the biomaterial field, the control of phases formed after laser processing remains the greatest challenge. Process control and the design of new powders will be key factors in improving osseointegration and biocompatibility with the human body.

Microstructures obtained after coating with composite materials remain very complex. Even the most refractory particles are partially dissolved by laser and incorporated into the metal matrix of TiAl titanium alloys and other high performance alloys. A thorough study of these reactions is essential to enable the design of new mixtures that inhibit the formation of undesirable compounds.

\section{ACKNOWLEDGMENTS}

The authors wish to acknowledge the Spanish Ministry of Science and Innovation for funding this research through Project No. MAT2008-06 882-C04-04 (part of the national minerals program). The authors also wish to acknowledge the support of the Generalitat Valenciana through Project No. ACOMP/2009/232. The translation of this paper was funded by the Universidad Politécnica de Valencia, Spain

${ }^{1}$ Y. S. Tian, C. Z. Chen, S. T. Li, and Q. H. Huo, "Research progress on laser surface modification of titanium alloys," Appl. Surf. Sci. 242, 177184 (2005).

${ }^{2} \mathrm{Lin} \mathrm{Li}$, "The advances and characteristics of high-power diode laser materials processing," Opt. Lasers Eng. 34, 231-253 (2000).

${ }^{3}$ L. Quintino, A. Costa, R. Miranda, D. Yapp, V. Kumar, and C. J. Kong, "Welding with high power fiber lasers-A preliminary study," Mater.
Des. 28, 1231-1237 (2007).

${ }^{4}$ H. Kim, R. Camata, S. Lee, G. Rohrer, A. D. Rollett, and Y. K. Vohra, "Crystallographic texture in pulsed laser deposited hydroxyapatite bioceramic coatings," Acta Mater. 55, 131-139 (2007).

${ }^{5}$ K. A. Khor, A. Vreeling, Z. I. Dong, and P. Cheang, "Laser treatment of plasma sprayed HA coatings," Mater. Sci. Eng., A 266, 1-7 (1999).

${ }^{6}$ C. Chen, D. Wang, Q. Bao, L. Zhang, and T. Lei, "Influence of laser remelting on the microstructure and phases constitution of plasma sprayed hydroxyapatite coatings," Appl. Surf. Sci. 250, 98-103 (2005). ${ }^{7}$ Y. Wang, Y. Li, H. Yu, and J. Ding, "In situ fabrication of bioceramic composite coatings by laser cladding," Surf. Coat. Technol. 200, 20802084 (2005).

${ }^{8}$ M. Zheng, D. Fan, X. Li, W. Li, Q. Liu, and J. Zhang, "Microstructure and osteoblast response of gradient bioceramic coating on titanium alloy fabricated by laser cladding," Appl. Surf. Sci. 255, 426-428 (2008).

${ }^{9}$ D. Wang, C. Chen, J. Ma, and T. Lei, "Microstructure of yttric calcium phosphate bioceramic coatings synthesized by laser cladding," Appl. Surf. Sci. 253, 4016-4020 (2007).

${ }^{10} \mathrm{M}$. Zheng, D. Fan, X. Li, J. Zhang, and Q. Liu, "Microstructure and in vitro bioactivity of laser-cladded bioceramic coating on titanium alloy in a simulated body fluid," J. Alloys Compd. 489, 211-214 (2010).

${ }^{11}$ R. Comesaña, F. Quintero, F. Lusquiños, and M. J. Pascual, "Laser cladding of bioactive glass coatings," Acta Biomater. 6, 953-961 (2010).

${ }^{12}$ L. Hao, J. Lawrence, and L. Li, "Manipulation of the osteoblast response to a Ti-6Al-4V titanium alloy using a high power diode laser," Appl. Surf. Sci. 247, 602-606 (2005).

${ }^{13}$ D. Wang, Z. Tian, L. Shen, Z. Liu, and Y. Huang, "Influences of laser remelting on microstructure of nanostructured Al2O3-13 wt.\% $\mathrm{TiO} 2$ coatings fabricated by plasma spraying," Appl. Surf. Sci. 255, 46064610 (2009).

${ }^{14}$ V. K. Balla, P. Duteil, W. Xue, S. Bose, and A. Bandyopadhyay, "Fabrication of compositionally and structurally graded $\mathrm{Ti}-\mathrm{TiO} 2$ structures using laser engineered net shaping," Acta Biomater. 5, 1831-1837 (2009). ${ }^{15}$ V. K. Balla, W. Xue, S. Bose, and A. Bandyopadhyay, "Laser-assisted $\mathrm{Zr} / \mathrm{ZrO} 2$ coating on Ti for load-bearing implants," Acta Biomater. 5, 2800-2809 (2009).

${ }^{16}$ Y. Xue and H. M. Wang, "Microstructure and wear properties of laser clad $\mathrm{TiCo} / \mathrm{Ti}_{2} \mathrm{Co}$ intermetallic coatings on titanium alloy," Appl. Surf. Sci. 243, 278-286 (2005).

${ }^{17}$ J. Dutta Majumdar, I. Manna, A. Kumar, P. Bhargava, and A. K. Nath, "Direct laser cladding of Co on Ti-6Al-4V with a compositionally graded interface," J. Mater. Process. Technol. 209, 2237-2243 (2009).

${ }^{18} \mathrm{~F}$. Gao and H. M. Wang, "Dry sliding wear property of a laser melting/ deposited Ti2Ni/TiNi intermetallic alloy," Intermetallics 16, 202-208 (2008).

${ }^{19}$ V. Fallah, S. F. Corbin, and A. Khajepour, "Solidification behaviour and phase formation during pre-placed laser cladding of Ti45Nb," Surf. Coat. Technol. 204, 2400-2409 (2010).

${ }^{20} \mathrm{H}$. Zhou, F. Li, B. He, J. Wang, and B. Sun, "Air plasma sprayed thermal barrier coatings on titanium alloy substrates," Surf. Coat. Technol. 201, 7360-7367 (2007).

${ }^{21} \mathrm{Q}$. Meng, L. Geng, and D. Ni, "Laser cladding NiCoCrAlY coating on Ti-6Al-4V," Mater. Lett. 59, 2774-2777 (2005).

${ }^{22} \mathrm{Y}$. Xue and H. M. Wang, "Microstructure and properties of Ti-Co-Si ternary intermetallic alloys," J. Alloys Compd. 464, 138-145 (2008).

${ }^{23}$ S. Sarkar, S. Datta, S. Das, and D. Basu, "Oxidation protection of gamma-titanium aluminide using glass-ceramic coatings," Surf. Coat. Technol. 203, 1797-1805 (2009).

${ }^{24} \mathrm{P}$. C. Tsai and C. S. Hsu, "High temperature corrosion resistance and microstructural evaluation of laser-glazed plasma-sprayed zirconia/ MCrAlY thermal barrier coatings," Surf. Coat. Technol. 183, 29-34 (2004).

${ }^{25}$ C. Batista, A. Portinha, R. M. Ribeiro, V. Teixeira, M. F. Costa, and C. R. Oliveira, "Surface laser-glazing of plasma-sprayed thermal barrier coatings," Appl. Surf. Sci. 247, 313-319 (2005).

${ }^{26}$ C. Batista, A. Portinha, R. M. Ribeiro, V. Teixeira, M. F. Costa, and C. R. Oliveira, "Morphological and microstructural characterization of laserglazed plasma-sprayed thermal barrier coatings," Surf. Coat. Technol. 200, 2929-2937 (2006).

${ }^{27}$ C. Batista, A. Portinha, R. M. Ribeiro, V. Teixeira, and C. R. Oliveira, "Evaluation of laser-glazed plasma-sprayed thermal barrier coatings under high temperature exposure to molten salts," Surf. Coat. Technol. 200, 6783-6791 (2006).

${ }^{28}$ R. Krishnan, S. Dash, R. Kesavamoorthy, C. Babu Rao, A. K. Tyagi, and 
B. Raj, "Laser surface modification and characterization of air plasma sprayed alumina coatings," Surf. Coat. Technol. 200, 2791-2799 (2006).

${ }^{29}$ T. Goto, "Thermal barrier coatings deposited by laser CVD," Surf. Coat. Technol. 198, 367-371 (2005).

${ }^{30}$ A. Ito, H. Kadokura, T. Kimura, and T. Goto, "Texture and orientation characteristics of $\alpha-\mathrm{Al}_{2} \mathrm{O}_{3}$ films prepared by laser chemical vapor deposition using Nd:YAG laser," J. Alloys Compd. 489, 469-474 (2010).

${ }^{31}$ O. Kessler, "Combination of coating and heat treatment processes," Surf. Coat. Technol. 201, 4046-4051 (2006).

${ }^{32}$ R. Braun, F. Rovere, P. H. Mayrhofer, and C. Leyens, "Environmental protection of $\mathrm{g}$-TiAl based alloy Ti-45Al-8Nb by CrAlYN thin films and thermal barrier coatings," Intermetallics 18, 479-486 (2010).

${ }^{33}$ I. Shishkovsky, Yu. Morozov, I. Yadroitsev, and I. Smurov, "Titanium and aluminum nitride synthesis via layer by layer LA-CVD," Appl. Surf. Sci. 255, 9847-9850 (2009).

${ }^{34}$ D. E. Alman and J. A. Hawk, "The abrasive wear of sintered titanium matrix-ceramic particle reinforced composites," Wear 225-229, 629-639 (1999).

${ }^{35}$ O. N. Dogan, J. A. Hawk, J. H. Tylczak, R. D. Wilson, and R. D. Govier, "Wear of titanium carbide reinforced metal matrix composites," Wear 225, 758-769 (1999).

${ }^{36}$ R. L. Sun, D. Z. Yang, L. X. Guo, and S. L. Dong, "Laser cladding of Ti-6Al-4V alloy with TiC and TiC-NiCrBSi powders," Surf. Coat. Technol. 135, 307-312 (2001).

${ }^{37} \mathrm{X}$. Wu and Y. Hong, "Microstructure and mechanical properties at $\mathrm{TiCp} /$ Ni-alloy interfaces in laser-synthesized coatings," Mater. Sci. Eng., A 318, 15-21 (2001).

${ }^{38}$ Q. W. Meng, L. Geng, and B. Y. Zhang, Laser cladding of Ni-base composite coatings onto Ti-6Al-4V substrates with pre-placed $\mathrm{B}_{4} \mathrm{C}$ +NiCrBSi powders," Surf. Coat. Technol. 200, 4923-4928 (2006).

${ }^{39}$ X. B. Liu and H. M. Wang, "Microstructure and tribological properties of laser clad $\gamma / \mathrm{Cr}_{7} \mathrm{C}_{3} / \mathrm{TiC}$ composite coatings on $\gamma$-TiAl intermetallic alloy," Wear 262, 514-521 (2007).

${ }^{40}$ Xiu-Bo Liu, Shi-Hong Shi, Jian Guo, Ge-Yan Fu, and Ming-Di Wang, Microstructure and wear behavior of $\gamma \mathrm{Al} 14 \mathrm{C} 3 / \mathrm{TiC} / \mathrm{CaF}_{2}$ composite coating on $\gamma$-TiAl intermetallic alloy prepared by Nd:YAG laser cladding," Appl. Surf. Sci. 255, 5662-5668 (2009).

${ }^{41}$ L. Cai, Y. Zhang, and L. Shi, "Microstructure and formation mechanism of titanium matrix composites coating on Ti-6A1-4V by laser cladding," Rare Met. 26, 342-346 (2007).

${ }^{42}$ Y. Yang, D. Zhang, W. Yan, and Y. Zheng, "Microstructure and wear properties of TiCN/Ti coatings on titanium alloy by laser cladding," Opt. Lasers Eng. 48, 119-124 (2010).

${ }^{43}$ A. F. Saleh, J. H. Abboud, and K. Y. Benyounis, "Surface carburizing of Ti-6Al-4V alloy by laser melting," Opt. Lasers Eng. 48, 257-267 (2010).
${ }^{44}$ Y. Xiong, J. E. Smugeresky, L. Ajdelsztajn, and J. M. Schoenung, "Fabrication of WC-Co cermets by laser engineered net shaping," Mater. Sci. Eng., A 493, 261-266 (2008).

${ }^{45}$ F. Wang, J. Mei, and X. Wu, "Microstructure study of direct laser fabricated Ti alloys using powder and wire," Appl. Surf. Sci. 253, 1424-1430 (2006).

${ }^{46}$ Y. Zhang, Z. Wei, L. Shi, and M. Xi, "Characterization of laser powder deposited Ti-TiC composites and functional gradient materials," J. Mater. Process. Technol. 206, 438-444 (2008).

${ }^{47}$ J. J. Candel, V. Amigó, J. A. Ramos, and D. Busquets, "Sliding wear resistance of TiCp reinforced titanium composite coating produced by laser cladding," Surf. Coat. Technol. 204, 3161-3166 (2010).

${ }^{48}$ H. Choe, S. M. Abkowitz, and D. C. Dunand, "Effect of tungsten additions on the mechanical properties of Ti-6Al-4V," Mater. Sci. Eng., A 396, 99-106 (2005).

${ }^{49}$ W. Pang, H. C. Man, and T. M. Yue, "Laser surface coating of Mo-WC metal matrix composite on Ti6Al4V alloy," Mater. Sci. Eng., A 390, 144-153 (2005).

${ }^{50}$ V. Ocelik, D. Matthews, and J. Th. M. De Hosson, "Sliding wear resistance of metal matrix composite layers prepared by high power laser," Surf. Coat. Technol. 197, 303-315 (2005).

${ }^{51}$ Y. Chen, D. Liu, F. Li, and L. Li, "WCp/Ti-6Al-4V graded metal matrix composites layer produced by laser melt injection," Surf. Coat. Technol. 202, 4780-4787 (2008).

${ }^{52}$ F. Wang, J. Mei, and X. Wu, "Direct laser fabrication of Ti6Al4V/TiB," J. Mater. Process. Technol. 195, 321-326 (2008).

${ }^{53}$ Y. S. Tian, C. Z. Chen, L. X. Chen, and Q. H. Huo, "Effect of RE oxides on the microstructure of the coatings fabricated on titanium alloys by laser alloying technique," Scr. Mater. 54, 847-852 (2006).

${ }^{54} \mathrm{P}$. A. Coulon and Gec Alsthom, "Resistance to wear of nitriding on titanium alloy using the laser-irradiation technique," J. Mater. Process. Technol. 38, 247-263 (1993).

${ }^{55}$ V. M. Weerasinghe, D. R. F. West, and J. de Damborenea, "Laser surface nitriding of titanium and a titanium alloy," J. Mater. Process. Technol. 58, 79-86 (1996)

${ }^{56}$ S. Sathish, M. Geetha, N. D. Pandey, C. Richard, and R. Asokamani, "Studies on the corrosion and wear behavior of the laser nitrided biomedical titanium and its alloys," Mater. Sci. Eng., C 30, 376-382 (2010).

${ }^{57}$ H. C. Man, S. Zhang, F. T. Cheng, and X. Guo, "In situ formation of a TiN/Ti metal matrix composite gradient coating on NiTi by laser cladding and nitriding," Surf. Coat. Technol. 200, 4961-4966 (2006).

${ }^{58}$ Y. Pu, B. Guo, J. Zhou, S. Zhang, H. Zhou, and J. Chen, "Microstructure and tribological properties of in situ synthesized $\mathrm{TiC}$, TiN, and $\mathrm{SiC}$ reinforced Ti3Al intermetallic matrix composite coatings on pure Ti by laser cladding," Appl. Surf. Sci. 255, 2697-2703 (2008) 